Article

\title{
Geospatial Distributions of Lead Levels Found in Human Hair and Preterm Birth in San Francisco Neighborhoods
}

\author{
Chinomnso N. Okorie ${ }^{1,2, *(\mathbb{D}, \text { Marilyn D. Thomas }}{ }^{3}$, Rebecca M. Méndez ${ }^{2}$, Erendira C. Di Giuseppe ${ }^{2}$, Nina S. Roberts ${ }^{4}$ \\ and Leticia Márquez-Magaña ${ }^{2}$ \\ 1 Department of Obstetrics, Gynecology, and Reproductive Sciences, University of California, \\ San Francisco, CA 94115, USA \\ 2 Department of Biology, San Francisco State University, San Francisco, CA 94132, USA; \\ rmmendez@sfsu.edu (R.M.M.); edigiuseppe@berkeley.edu (E.C.D.G.); marquez@sfsu.edu (L.M.-M.) \\ 3 Departments of Epidemiology, and Biostatistics, Psychiatry and Behavioral Sciences, University of California, \\ San Francisco, CA 94107, USA; Marilyn.Thomas@ucsf.edu \\ 4 Department of Recreation, Parks and Tourism, San Francisco State University, San Francisco, CA 94132, USA; \\ nroberts@sfsu.edu \\ * Correspondence: chinomnso.okorie@ucsf.edu
}

\section{check for}

updates

Citation: Okorie, C.N.; Thomas, M.D.; Méndez, R.M.; Di Giuseppe, E.C.; Roberts, N.S.; Márquez-Magaña, L. Geospatial Distributions of Lead Levels Found in Human Hair and Preterm Birth in San Francisco Neighborhoods. Int. J. Environ. Res. Public Health 2022, 19, 86. https:/ / doi.org/10.3390/ijerph19010086

Academic Editors: Walter Mazzucco and Paolo Contiero

Received: 21 November 2021

Accepted: 6 December 2021

Published: 22 December 2021

Publisher's Note: MDPI stays neutral with regard to jurisdictional claims in published maps and institutional affiliations.

Copyright: (c) 2021 by the authors Licensee MDPI, Basel, Switzerland. This article is an open access article distributed under the terms and conditions of the Creative Commons Attribution (CC BY) license (https:// creativecommons.org/licenses/by/ $4.0 /)$.

\begin{abstract}
In San Francisco (SF), many environmental factors drive the unequal burden of preterm birth outcomes for communities of color. Here, we examine the association between human exposure to lead $(\mathrm{Pb})$ and preterm birth $(\mathrm{PTB})$ in 19 racially diverse SF zip codes. Pb concentrations were measured in 109 hair samples donated by 72 salons and barbershops in 2018-2019. Multi-method data collection included randomly selecting hair salons stratified by zip code, administering demographic surveys, and measuring $\mathrm{Pb}$ in hair samples as a biomarker of environmental exposure to heavy metals. Concentrations of $\mathrm{Pb}$ were measured by atomic emission spectrometry. Aggregate neighborhood $\mathrm{Pb}$ levels were linked to PTB and demographic data using STATA 16 SE (StataCorp LLC, College Station, TX, USA). Pb varied by zip code $(p<0.001)$ and correlated with PTB $(p<0.01)$. Increases in unadjusted $\mathrm{Pb}$ concentration predicted an increase in PTB $(\beta=0.003 ; p<0.001)$ and after adjusting for poverty $(\beta=0.002 ; p<0.001)$. Confidence intervals contained the null after further adjustment for African American/Black population density $(p=0.16)$, suggesting that race is more indicative of high rates of $\mathrm{PTB}$ than poverty. In conclusion, $\mathrm{Pb}$ was found in every hair sample collected from SF neighborhoods. The highest concentrations were found in predominately African American/Black and high poverty neighborhoods, necessitating public health guidelines to eliminate this environmental injustice.
\end{abstract}

Keywords: lead exposure; preterm birth; environmental racism; heavy metals; environmental pollution; urban contaminants; environmental justice; African American/Blacks; hair samples

\section{Introduction}

Preterm birth (PTB) is well known as the most common cause of infant death and is the leading cause of disability-adjusted life years in the United States [1]. It is triggered by multiple pathological processes, including exposure to environmental factors [1]. Moreover, preliminary studies suggest that exposure to environmental toxins, such as lead $(\mathrm{Pb})$, are associated with pregnancy complications, including PTB [2-4]. Notably, in San Francisco, the prevalence of PTB is significantly higher in low-income neighborhoods compared to high-income neighborhoods [5]. Social determinants of health conditions in the environments in which people are born, live, learn, work, play, worship, and age affect a wide range of health, functioning, and quality of life outcomes and risks. The range of personal, social, economic, and environmental factors influence the health status of individuals $[2,6]$. However, the interactions between the determinants of health such as race/ethnicity, poverty, environmental exposure to $\mathrm{Pb}$ and $\mathrm{PTB}$ rates are undefined. To address this gap in knowledge, this study examined environmental exposure of humans to $\mathrm{Pb}$ by measuring 
its concentration in hair and its correlations to PTB rates, race, and poverty for zip codes in San Francisco.

San Francisco (SF), like much of the world during the industrial era, relied on $\mathrm{Pb}$ to manufacture gasoline, paint, and pipes transporting water $[3,7,8]$. Lead-containing water pipes in older buildings, paint, and toxic waste from oil refineries are still present in the built-environment today in older cities like SF. For example, the SF Naval Radiological Defense Laboratory (NRDL) was operational from 1945 to 1974. NRDL activities contaminated soil, dust, sediments, surface water, and groundwater with petroleum fuels, pesticides, polychlorinated biphenyls, volatile organic compounds, radionuclides, and heavy metals such as $\mathrm{Pb}$ [9-11]. Superfund sites such as NRDL are found near low-income neighborhoods, including Bayview Hunters Point, which is predominantly African American/Black [9-11].

The burden of PTB on low-income and racially minoritized communities is apparent, and their location near environmental hazard sewage, waste, and hazard sites is clear $[1,11,12]$. Pervasive exposure to environmental toxins and ongoing racial inequities indisputably affect birth rates. PTB rates are disproportionately higher in racially minoritized populations and low-income neighborhoods compared to white and higher-income communities [5]. These trends are also found in SF neighborhoods where PTB rates exceed $8.0 \%$ of all live births and are higher in areas with greater poverty [5]. Low-income neighborhoods in SF not only suffer from significantly higher PTB rates, but the ratio of premature infants born to African American/Black, Latinx, and White mothers is 3:2:1, respectively [5].

In addition to the sites' proximity to low-income communities, these populations have compounding exposure to health hazards by living in poor conditions. Poor living conditions is the reality for many non-White racial/ethnic groups which includes living in housing units built before the ban on $\mathrm{Pb}$ in the 1970s [7,9,11]. This includes neighborhoods such as Bayview Hunters Point, where the majority of African-American families reside in $\mathrm{SF}$, where the soil contains unacceptable levels of toxic environmental chemicals, raising questions about the efficacy of the clean-up efforts used for their disposal [9]. It also raises questions about the level of human exposure to heavy metals in this neighborhood and others in SF.

Multiple studies have shown that hair readily uptakes some heavy metals [12-15]. Researchers postulate that the shuttling of $\mathrm{Pb}$ to hair may be an effective method that the human body uses to detoxify [13,15-18]. Thus, the concentration of $\mathrm{Pb}$ in hair is an indicator of long-term environmental exposure to this toxic heavy metal [12,15]. Prolonged exposure to $\mathrm{Pb}$ has been linked to a myriad of adverse health outcomes, including disruption of fertility and pregnancy $[19,20]$. Studies show that exposure to toxic chemicals in the environment can accumulate over time in the mother's body and deposit in the fetus during pregnancy, ultimately resulting in PTB [1,19-21].

We evaluated the association between PTB and neighborhood-level $\mathrm{Pb}$ in the presence of other factors by using hair samples gathered from randomly selected neighborhood salons. According to survey results obtained from salon clients and staff, the hair gathered was from clients residing in these neighborhoods. We predicted that $\mathrm{Pb}$ concentrations in the collected hair would correlate with racial disparities in PTB outcomes for women residing in SF neighborhoods with high chemical waste sites and a greater prevalence of older homes.

\section{Materials and Methods}

This ecological-based observational study was designed to determine the relationship between PTB rates and Pb in hair collected from SF neighborhoods. Data collection consisted of a multi-method process including randomly selecting hair salons stratified by zip code, administering a brief in-house survey to record the clientele's demographics, followed by isolating $\mathrm{Pb}$ from donated hair samples. Pb levels, demographic data, and publicly available public health data were analyzed using statistical software. 


\subsection{Participants and Study Design}

The target population included 125 SF salons randomly selected across 26 zip codes (representing approximately $10 \%$ of hair salons in SF). The data generated from the successful collection of 109 donated samples from 72 salons (58\%) across 19 zip codes (73\%) of the target population (Figure 1). Zip codes were used as a proxy for neighborhoods because of the availability of PTB rate data [2]. Each participating establishment was categorized by service type (hair salons, hairstylists, and barbershops).

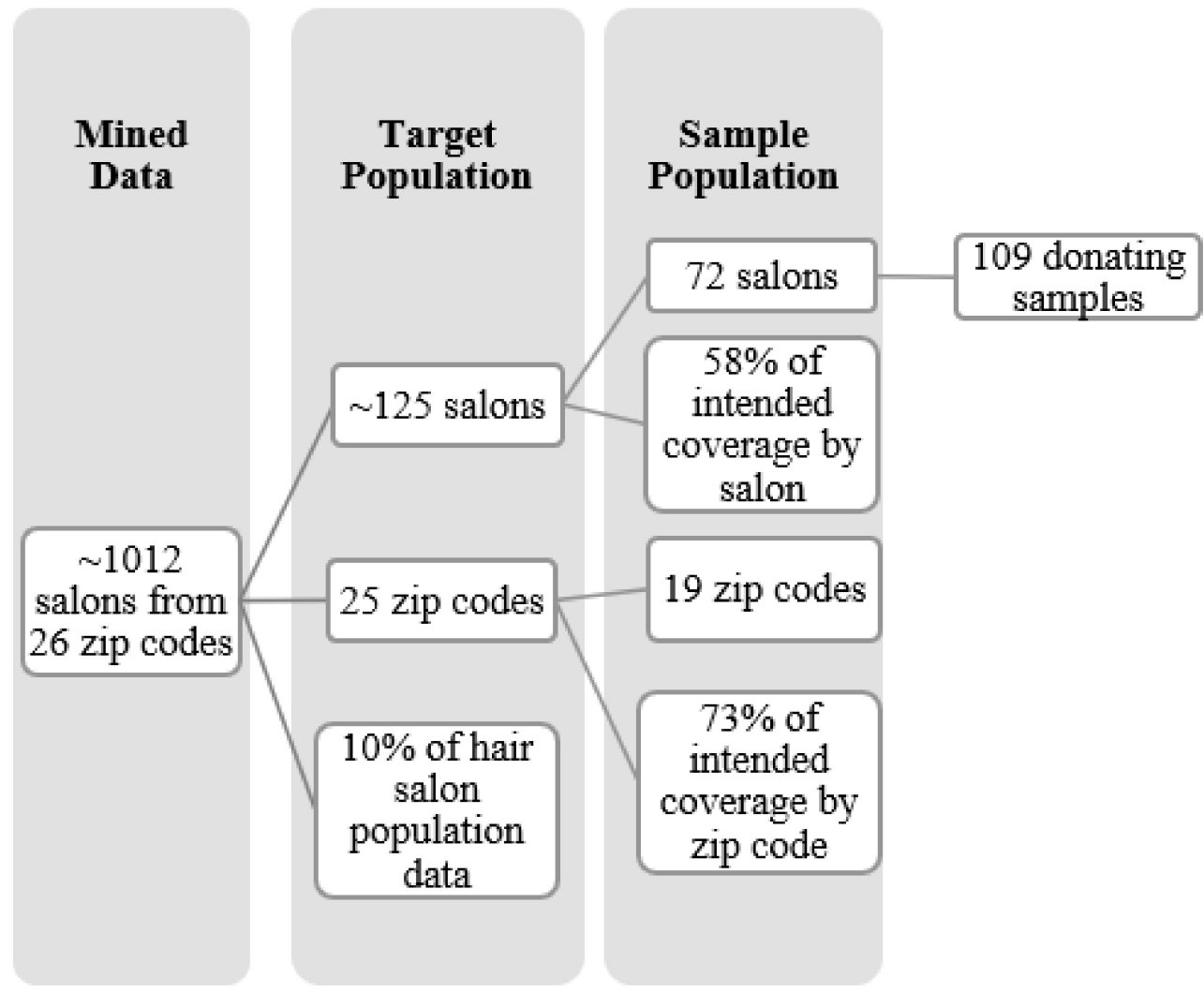

Figure 1. Sampling plan for selecting hair salons by zip code.

\subsection{Biospecimen Collection and Processing Procedures}

\subsubsection{Random Selection of Salons}

The data scraping software, Octoparse (v. 7.0.2, Octopus Data Inc., Diamond Bar, CA, USA), was used to identify Beauty and Barber salons/shops in SF via two search engines, Google (general) and Yelp (local). To scrape for hair salon/beauty salon/barbershops, the two inclusion criteria were the following: (1) be located in one of the 26 SF zip codes with known PTB rates, and (2) be identified as a registered establishment by the SF Business portal or a hairstylist with a permit who rents a chair at a registered establishment. The 1012 establishments that met the inclusion criteria were used in Octoparse analyses by using salon data (name, neighborhood/area, address, zip code, service type).

To determine the average number of salons to sample per zip code, a statistical software, RStudio (v. 1.1, RStudio PBC, Boston, MA, USA), generated a random distribution of five salons in each zip code. This randomized quota sampling method helped account for changes in population density across the city and gave rise to aggregated values for each population by zip code. Ultimately, a random list of 125 salons in SF was generated and used as recruitment spaces for biospecimen collection (Figure 1). The intent was to collect samples from $10 \%(n=125$ salons) of the hair salon population in SF $(n=1012)$, with a sample size skewed between (Population size (N): 1012, Confidence Interval (CI): 90\%, margin of error (E): 10\%) 64 salons and (N: 1012, CI: 99\%, E: 10\%) 143 salons. This study sampled at the lower end by collecting hair from 72 salons and 109 samples. Treasure Island, 
Alcatraz, and Farallon Islands were excluded since they did not meet the quota sampling of number of hair salons per zip code.

\subsubsection{Collection of Hair Samples}

To confirm inclusion criterion, selected sample sites were contacted by phone to verify operating hours and if the business catered predominately to local residents and/or clients who work in the SF more than eight hours in the city (i.e., occupational exposure) $[19,22,23]$.

Each client willing to participate was verbally consented and gave the authorization for the research team to collect hair samples. When no client was present, the business owner was consented. At minimum, the business owner was consented to record the demographics of clientele who, on average, visited the hair salon. This was necessary to record in order to account for the limitation that the hair collected belonged only to residents of that zip code.

After consent, laminated infographics designed for low literacy settings were disseminated to store owners, staff, and clientele. Each sheet provided information about environmental exposure and resources to increase awareness, facilitate conversations, and continue discussions with clientele around environmental exposure and possible health outcomes, consequently promoting trust between researchers and members of the community.

In addition, a 10-min interview in a survey format was administered to the consenting staff to understand the demographics of the general clientele population. The survey collected general information about the type of hair salon, cost of service, and locality of hair salon, sex, and race of customers used internally for verification. All responses were recorded on a digital device.

Then hair samples were collected by research staff filling a $250 \mathrm{~mL}$ container labeled high-density polyethylene with a mixture of trimmed hair from the floor or trash bin. The containers were stored at room temperature until processing. Survey data and biospecimens were de-identified to maintain privacy and confidentiality but were linked to the zip code where they were obtained for statistical analyses.

\subsubsection{Processing of Hair and $\mathrm{Pb}$ Measurement}

De-identified hair samples labeled with a code linking them to the zip code were obtained, survey responses gathered during collection were processed, and $\mathrm{Pb}$ concentrations were measured. Acetone was used to wash hair samples donated from each salon to remove foreign impurities on the surface, before pulverizing in a Mixer Mill (MM 400, Retsch $\mathrm{GmbH}$, Haan, Germany). Approximately $1.000 \mathrm{~g} \pm 0.100 \mathrm{~g}$ of pulverized hair before digestion with a 1:1 ratio of $100 \%$ nitric acid and deionized water to isolate the inorganic metals that accumulate in the hair shaft after environmental exposure. This technique allowed for the measurement of $\mathrm{Pb}$ within the shaft of the hair and not the surface. The digested products were analyzed using an Agilent model 4200 Microwave Plasma-Atomic Emission Spectrometry (MP-AES, Agilent, Santa Clara, CA, USA) system optimized for measurement of $\mathrm{Pb}$. Optimization for $\mathrm{Pb}$ quantification first required the calibration of the instrument response using $\mathrm{Pb}$ standards ranging from 0-10 parts-per-million (ppm). The $\mathrm{Pb}$ standards were prepared by gravimetric dilution of SPEX CertiPrep stock solutions (Spex SamplePrep LLC, Metuchen, NJ, USA) to generate calibration curves. The calibration curves were used to quantify $\mathrm{Pb}$ in the digested hair at the emission intensity of $405.781 \mathrm{~nm}$.

At $405.781 \mathrm{~nm}$, the limit of detection was $4 \mathrm{ppb}(0.004 \mathrm{ug} / \mathrm{g})$. Therefore, only measurements of $\mathrm{Pb}$ in hair greater than $4 \mathrm{ppb}$ were deemed reliable and then used to determine $\mathrm{Pb}$ concentration. $\mathrm{Pb}$ concentration was quantified in all hair samples at levels above our limit of detection (Supplementary Material, Figure S1). These measurements were converted from emission intensity into the appropriate units (i.e., ug/g). Quality Assurance/Quality Control (QA/QC) procedures were implemented to ensure the reliability of the results, including analysis of appropriate Standard Reference Materials (SRMs/CRMs) to assess accuracy and analysis of triplicate samples to assess precision. 


\subsection{Data Analyses and Visualization}

\subsubsection{Sources of Data and Statistical Analyses}

Birth Data from the 2012 San Francisco Department of Public Health was used to measure PTB rate [2]. The 2016 American Community Survey was used to measure neighborhood percent poverty, percent with a bachelor's degree, Gini index, percent African American/Black population, and foreign-born by zip code for assessment as confounders [24]. The association between $\mathrm{Pb}$ concentrations in inorganic extracts of hair and PTB in SF neighborhoods was determined using STATA 16 SE (StataCorp LLC, College Station, TX, USA). This software was used to conduct descriptive statistics, tests of mean differences (i.e., $t$-test, ANOVA), Pearson correlations, and linear regression models estimating the association between $\mathrm{Pb}$ and $\mathrm{PTB}$ adjusted for covariates significant at $p<0.05$. The covariates adjusted for are the confounders identified from the 2016 American Community Survey mentioned above. Pb levels were also estimated using a 3-level ordinal variable (25th and 75th percentile cut-points) to confirm linearity. PTB rates and poverty percentages were used to measure statistical correlations.

\subsubsection{Data Visualization}

ArcGIS geospatial mapping software (v. 2.2, Redlands, CA, USA) was used to visualize the distributions of $\mathrm{Pb}$ concentration and percent $\mathrm{PTB}$, poverty, and African American/Black population by neighborhood (i.e., zip code). Each of these determinants formed a layer on a map of SF, allowing "hot spots" to be readily identified. Consequently, this data visualization approach is highly appropriate for place-based studies aiming to share environmental research results to improve public health.

\section{Results}

Overall, Pb levels varied by neighborhood and correlated with PTB rates. Increases in $\mathrm{Pb}$ concentration predicted an increase in $\mathrm{PTB}$ after adjusting for poverty. However, $\mathrm{Pb}$ concentration compared to PTB became non-significant after further adjustment for percent African American/Black population.

\subsection{Pb Concentrations in Human Hair and Social Determinants Distribution in San Francisco}

$\mathrm{Pb}$ amounts were detected in all samples, ranging from $1.5 \mathrm{ug} / \mathrm{g}$ to $40 \mathrm{ug} / \mathrm{g}$, with a mean of $4.7 \mathrm{ug} / \mathrm{g} \pm 2.5 \mathrm{using}$ a $0.4 \mathrm{ug} / \mathrm{g}$ of $\mathrm{Pb}$ limit of detection reading from MP-AES instrument (Agilent, Santa Clara, CA, USA). For participating zip codes, the mean PTB percentage was $9.0 \% \pm 2.4$. The mean poverty rate was $13.3 \% \pm 6.3$, for bachelor's degree $34.3 \% \pm 7.7$, for Gini index 50.2\% \pm 6.3, for African American/Black population 6.0\% \pm 6.2 , and for foreign-born $32.3 \% \pm 11.3$ within the participating regions (Supplementary Material, Table S1). Hairstylists reported that most of their clients were female-presenting and were from the same and/or adjacent neighborhoods as the establishment.

\subsection{Poverty and PTB Distribution in SF}

There was a significant positive correlation $\left(\mathrm{R}^{2}\right.$ value $\left.=0.23 ; p=0.01\right)$ between neighborhood percent poverty and PTB rates (Figure 2, Table 1). Comparable to state-level and national-level averages $(9.0 \%$ and $9.9 \%$, respectively), the following neighborhoods had PTB rates above $9.0 \%$ : Treasure Island, South of Market, Bayview Hunters Point, Lake Merced/Merced Manor/Lake Shore, North Market/Hayes Valley/Tenderloin, St. Francis Wood/West Portal/Miraloma, Haight-Asbury/Hayes Valley, Visitacion Valley/Portola, Castro/Noe Valley/Corona Heights, Excelsior/Ocean View/Ingleside, Western Addition/Pacific Heights [5,22,25].

\subsection{Relationship between Pb Concentrations and Preterm Birth Rate, Education, and Ethnicity}

A pairwise analysis showed $\mathrm{Pb}$ concentration was correlated by neighborhood (adjusted $\left.\mathrm{R}^{2}=0.28 ; p<0.001\right)$, and was weakly correlated with PTB rates $(r=0.27 ; p<0.01)$, and with percent African American/Black population $(r=0.40 ; p<0.001)$ (Table 2). These results 
were consistent with an unpaired $t$-test (two-sample $t$-test with unequal variances) that showed significant mean differences in $\mathrm{Pb}$ concentration by $\mathrm{PTB}$, poverty, African American/Black population, foreign-born, bachelor's degree, and Gini index $(p<0.001)$ (Supplementary Table S2). However, there was no significant correlation between Pb levels and percent foreign-born nor with poverty $(p>0.05)$.

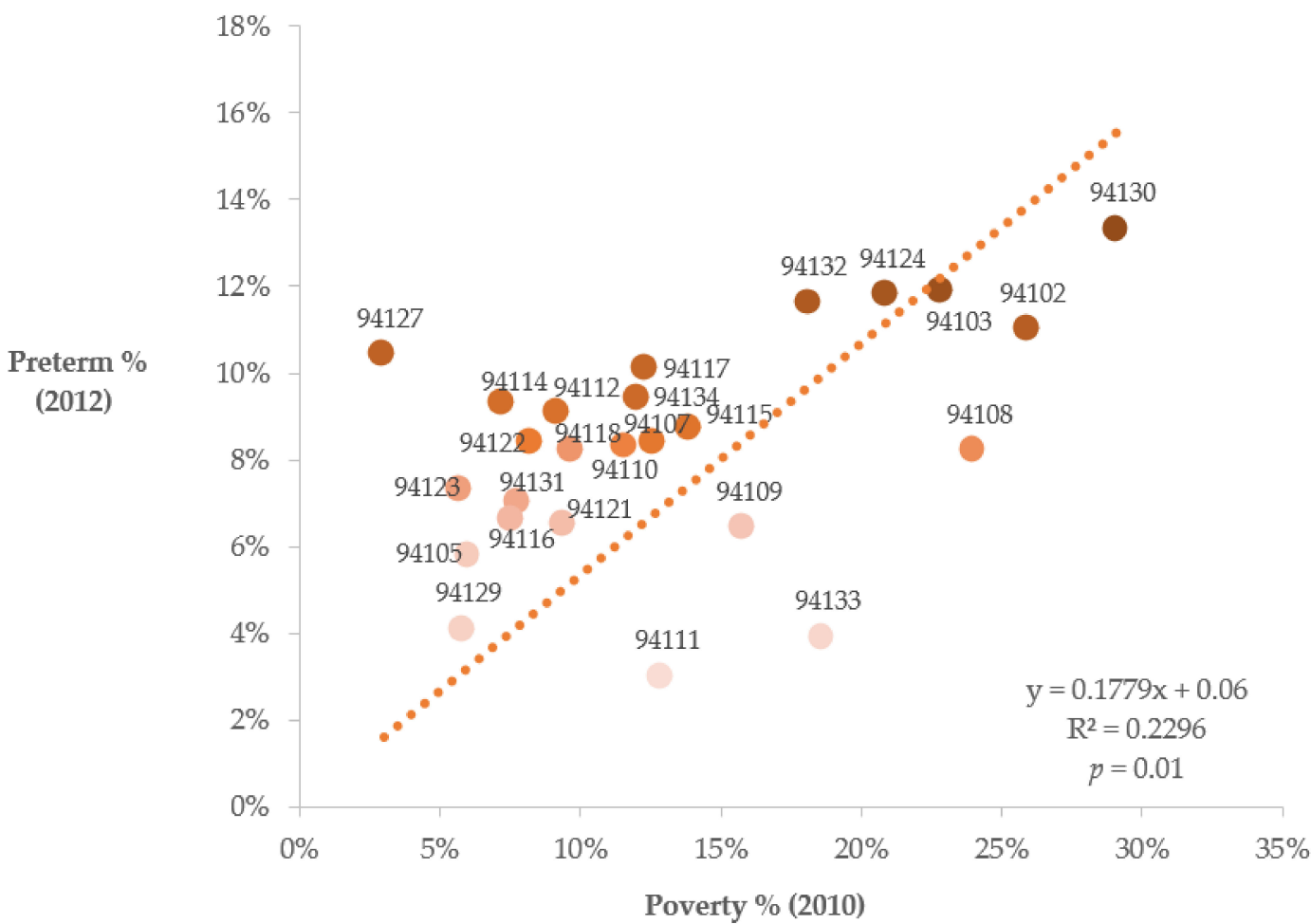

Figure 2. The correlation between percent PTB ( $y$-axis) and percent poverty $(x$-axis) by neighborhood (zip code) in SF with a significant $p$-value $(0.01)$ and $\mathrm{R}^{2}$ value $=0.23$ positive correlation trends. The darker the gradient color, the higher PTB \% and Poverty \%,y = Preterm \% (2012), $x=$ Poverty $\%(2010)$.

Nested regression models showed that a one-unit increase in $\mathrm{Pb}$ concentration predicted a rise in PTB in the unadjusted model $(\beta=0.003 ; p<0.001)$, and after adjusting for percent poverty $(\beta=0.002 ; p<0.001)$. Results became non-significant after further adjustment for percent African American/Black population $(\beta=0.001 ; p<0.16)$ (Supplementary Table S3). Similarly, a positive dose-response was found when $\mathrm{Pb}$ was assessed categorically in the unadjusted models (Supplementary Table S4): Compared to lower Pb levels $(<3.0 \mathrm{ug} / \mathrm{g})$, higher PTB was weakly associated with moderate levels of $\mathrm{Pb}(3-5.7 \mathrm{ug} / \mathrm{g}: \beta=0.011 ; p=0.067)$ and significant at the highest levels of $\mathrm{Pb}(>5.7 \mathrm{ug} / \mathrm{g}$ : $\beta=0.014 ; p<0.05)$. Results also became non-significant after adjustment for percent poverty and African American/Black population (both $\beta=0.007 ; p \approx 0.20$ ), showing race is more indicative of high PTB rates than poverty level, further discussed.

\subsection{Geospatial Representation of the Distribution of Pb in San Francisco}

Figure 3 represents the geographical distribution of $\mathrm{Pb}, \mathrm{PTB}$ rates, poverty rates, and African American/Black population density. Maps A-C show the distribution of PTB across zip codes in a blue base layer with darker tones reflecting higher PTB rates. Map A shows an overlapping dot distribution of poverty rates in purple. Map B shows an overlapping dot distribution of $\mathrm{Pb}$ concentration from hair samples in grey. Map $\mathrm{C}$ shows the overlapping dot distribution of $\mathrm{Pb}$ concentration and a heat map of African American/Black population density. Denser African American/Black population is reflected by the darker blue of the heat map. 
Table 1. SF neighborhoods and their zip code referenced.

\begin{tabular}{|c|c|}
\hline Zip Code & Neighborhood \\
\hline 94130 & Treasure Island \\
\hline 94103 & South of Market \\
\hline 94124 & Bayview/Hunters Point \\
\hline 94132 & Lake Merced/Merced Manor/Lake Shore \\
\hline 94102 & North Market/Hayes Valley/Tenderloin \\
\hline 94127 & St. Francis Wood/West Portal/Miraloma \\
\hline 94117 & Haight-Asbury/Hayes Valley \\
\hline 94134 & Visitacion Valley/Portola \\
\hline 94114 & Castro/Noe Valley/Corona Heights \\
\hline 94112 & Excelsior/Ocean View/Ingleside \\
\hline 94115 & Western Addition/Pacific Heights \\
\hline 94107 & Potrero Hill \\
\hline 94122 & Sunset \\
\hline 94110 & Mission/Bernal Heights \\
\hline 94108 & Chinatown \\
\hline 94118 & Inner Richmond/Presidio \\
\hline 94123 & Marina/Cow Hollow \\
\hline 94131 & Twin Peaks/Diamond Heights/Glen Park \\
\hline 94158 & South of Market/Mission Bay \\
\hline 94116 & Parkside/Forest Hill \\
\hline 94121 & Richmond/Sea Cliff \\
\hline 94109 & Nob Hill/Russian Hill/Tenderloin \\
\hline 94105 & Financial District \\
\hline 94129 & Presidio \\
\hline 94133 & North Beach/Telegraph Hill \\
\hline 94111 & Embarcadero \\
\hline
\end{tabular}

Table 2. Pearson correlations with significant values underneath estimates.

\begin{tabular}{|c|c|c|c|c|c|c|c|c|}
\hline & $\begin{array}{c}\mathrm{Pb} \\
\text { Concentration }\end{array}$ & $\begin{array}{l}\text { Preterm } \\
\text { Birth }\end{array}$ & Zip Code & $\begin{array}{l}\text { African American/ } \\
\text { Black Population }\end{array}$ & $\begin{array}{l}\text { Foreign- } \\
\text { Born }\end{array}$ & $\begin{array}{l}\text { Bachelor's } \\
\text { Degree }\end{array}$ & Poverty & $\begin{array}{l}\text { Gini } \\
\text { Index }\end{array}$ \\
\hline $\mathrm{Pb}$ Concentration & 1.0000 & & & & & & & \\
\hline Preterm Birth & $\begin{array}{l}0.2749 \\
1.0000\end{array}$ & 1.0000 & & & & & & \\
\hline Zip Code & $\begin{array}{l}0.0965 \\
0.3204\end{array}$ & $\begin{array}{c}-0.1168 \\
0.2286\end{array}$ & 1.0000 & & & & & \\
\hline $\begin{array}{l}\text { African American/ } \\
\text { Black Population }\end{array}$ & $\begin{array}{l}0.4023 \\
0.0000\end{array}$ & $\begin{array}{l}0.4831 \\
0.0000\end{array}$ & $\begin{array}{l}0.0750 \\
0.4404\end{array}$ & 1.0000 & & & & \\
\hline Foreign-Born & $\begin{array}{l}0.0170 \\
0.8614\end{array}$ & $\begin{array}{l}0.0649 \\
0.5043\end{array}$ & $\begin{array}{c}-0.4481 \\
0.0000\end{array}$ & $\begin{array}{l}0.1428 \\
0.1403\end{array}$ & 1.0000 & & & \\
\hline Bachelor's Degree & $\begin{array}{c}-0.2204 \\
0.0219\end{array}$ & $\begin{array}{c}-0.2775 \\
0.0036\end{array}$ & $\begin{array}{l}0.2374 \\
0.0134\end{array}$ & $\begin{array}{c}-0.5340 \\
0.0000\end{array}$ & $\begin{array}{c}-0.6169 \\
0.0000\end{array}$ & 1.0000 & & \\
\hline Poverty & $\begin{array}{l}0.1055 \\
0.2771\end{array}$ & $\begin{array}{l}0.3511 \\
0.0002\end{array}$ & $\begin{array}{c}-0.2879 \\
0.0025\end{array}$ & $\begin{array}{l}0.5216 \\
0.0000\end{array}$ & $\begin{array}{l}0.5401 \\
0.0000\end{array}$ & $\begin{array}{c}-0.6169 \\
0.0000\end{array}$ & 1.0000 & \\
\hline Gini Index & $\begin{array}{c}-0.0094 \\
0.9233\end{array}$ & $\begin{array}{c}-0.0298 \\
0.7592\end{array}$ & $\begin{array}{c}-0.1786 \\
0.0644\end{array}$ & $\begin{array}{l}0.1977 \\
0.0402\end{array}$ & $\begin{array}{l}0.1980 \\
0.0400\end{array}$ & $\begin{array}{c}-0.2692 \\
0.0048\end{array}$ & $\begin{array}{l}0.7461 \\
0.0000\end{array}$ & 1.0000 \\
\hline
\end{tabular}




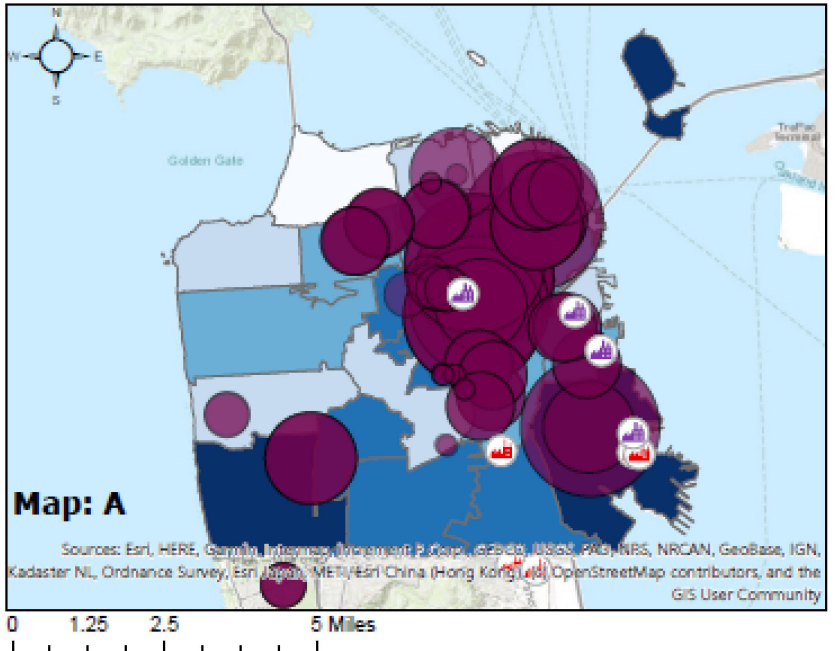

\section{Legend}

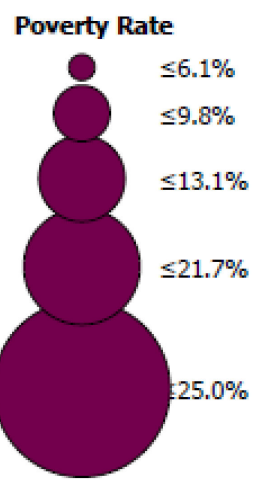

Preterm Birth Rate
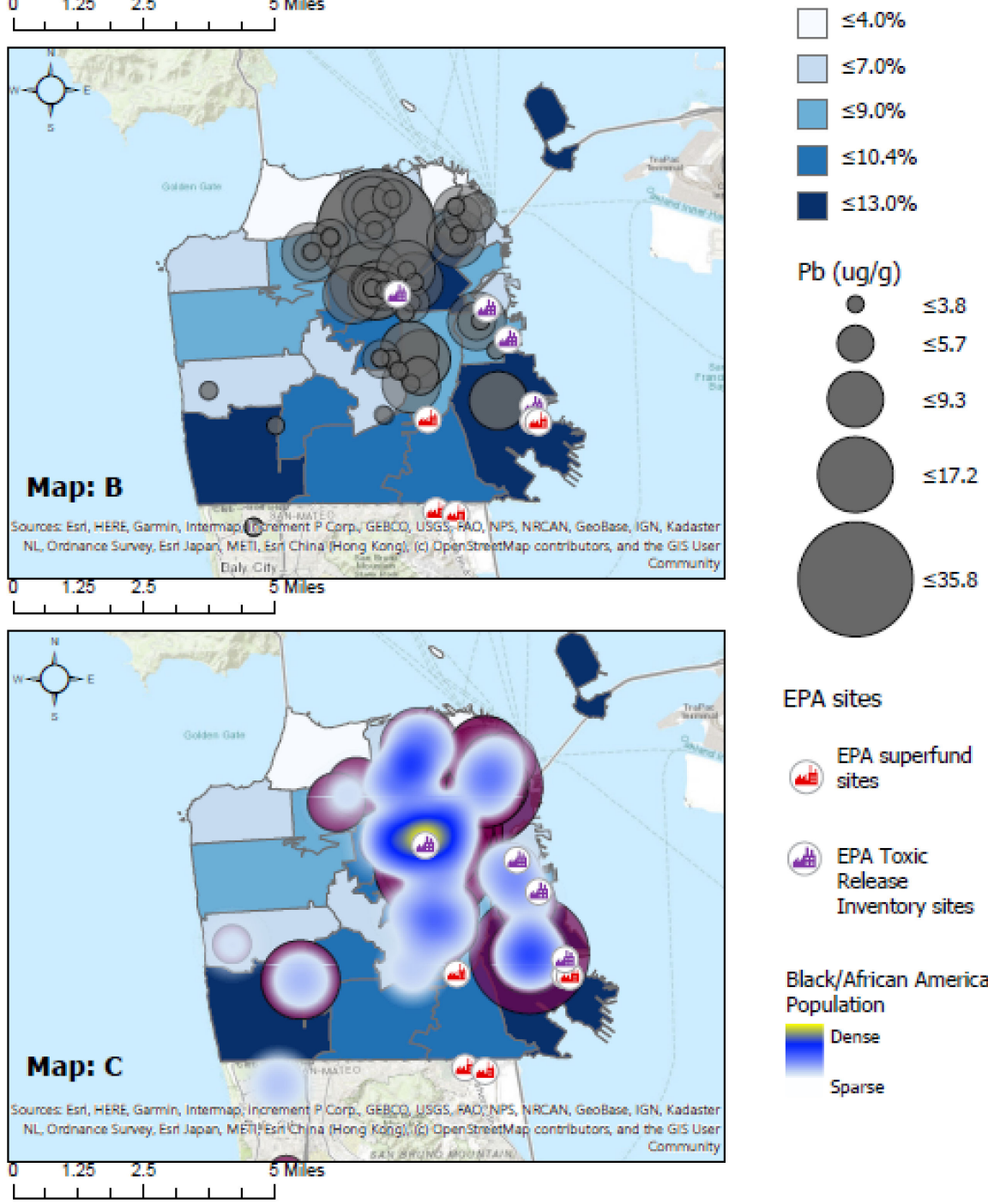

\section{EPA sites}

EPA superfund

ali) sites

iii) EPA Toxic

Release

Inventory sites

Black/African American Population

Dense

Sparse

Figure 3. Geographic Distribution of $\mathrm{Pb}$ and Social Determinants in San Francisco by zip code. The layers are as follows: a polygon base layer of zip codes with their PTB rate in blue (Maps A-C), a purple dot distribution of poverty rates (Maps A,C), a grey dot distribution of $\mathrm{Pb}$ concentration $\mathrm{Pb}$ (ug/g) by hair salons (Map B), and a heat map of African American/Black population density (Map C). Black, red, purple icons (Maps A-C) illustrate EPA sites. Note that zip code 94015 is shared with Daly City and only PTB data exist for Treasure Island), EPA = U.S. Environmental Protection Agency. 
PTB rates were concentrated South of SF $\left(-122^{\circ} 25^{\prime} \mathrm{S}\right)$ and most heavily in the Southwest $\left(37^{\circ} 44^{\prime} \mathrm{W},-122^{\circ} 25^{\prime} \mathrm{S}\right)$ and Southeast $\left(37^{\circ} 44^{\prime} \mathrm{E},-122^{\circ} 25^{\prime} \mathrm{S}\right)$. High poverty rates, high levels $\mathrm{Pb}$ exposure, and dense African American/Black population were concentrated East of SF $\left(37^{\circ} 44^{\prime} \mathrm{E}\right)$. These trends appear most heavily in Northeast $\left(37^{\circ} 48^{\prime} \mathrm{E},-122^{\circ} 26^{\prime} \mathrm{N}\right)$ and Southeast $\left(37^{\circ} 44^{\prime} \mathrm{E},-122^{\circ} 26^{\prime} \mathrm{S}\right)$ as shown by Figure 3, Map A, B, and C respectively.

\section{Discussion}

\subsection{Primary Findings}

The primary finding is that the majority of hair samples obtained from different SF neighborhoods contained a concentration of $\mathrm{Pb}$ within the hair shaft accumulated over time. The highest $\mathrm{Pb}$ exposure was measured in Eastern SF, predominantly in the Southeast neighborhoods, where a large population of African American/Black resides, and PTB rates soar. Additionally, PTB rates were higher in neighborhood pockets encompassing hazardous waste sites, high poverty rates, and racial/ethnic communities. This important study highlights the need for more translational community participatory research to help bridge the gap between basic science and epidemiological research to illustrate a clear picture of health disparities.

This is the first ecological study to measure $\mathrm{Pb}$ exposure in San Francisco (SF) using a novel, low-invasive hair sample approach to investigate correlations between $\mathrm{Pb}$ concentration, PTB, and neighborhood determinants of health. The use of hair salons as a focal point for community engagement allowed us to be innovative in exploring the knowledge gap in understanding correlations between human exposure to heavy metals in SF neighborhoods and PTB across multiple levels. The average Pb concentration detected in hair samples $(n=108)$ was $4.7 \mathrm{ug} / \mathrm{g}( \pm 2.5)$ from 72 hair salons spread across $58 \%$ of SF county. When $\mathrm{Pb}$ concentrations were aggregated by zip code, $\mathrm{Pb}$ concentrations were significantly and positively associated with PTB rates and African American/Black population density. Furthermore, higher poverty percentages modestly trended with higher PTB. Additionally, negative correlations were found between $\mathrm{Pb}$ concentration and both bachelor's degree attainment and Gini index, but they were statistically non-significant and thus weakly correlated (Table 2).

Overall, results of this present study show that high $\mathrm{Pb}$ exposure was found in San Francisco neighborhoods with larger numbers of African American/Blacks and higher preterm birth rates. Predominantly African American/Black communities experience historical and ongoing neglect and divestment that contribute to disproportionate exposure to high-risk factors, including poverty and environmental toxins leading to health disparities. For example, African American/Black families are more likely to live in poor areas with dilapidated housing and/or old infrastructure (e.g., paint/pipes) increasing their risk for environmental toxin exposure [23]. This further explains why we found a moderate correlation between poverty and percent African American/Black population $(r=0.52)$. Together our findings suggest that interventions aimed to address the negative impact that $\mathrm{Pb}$ exposure may have on PTB should target poor African American communities.

The association between $\mathrm{PTB}$ and $\mathrm{Pb}$ became non-significant in the linear regression models adjusted for poverty when percent African American population was added. It seems that the effects of poverty reduced in the presence of race in dense concentrated areas with high PTB. As seen geospatially, race becomes a determining factor for PTB. This finding aligns with the effects of racism on African American/Black communities, which prevent them from attaining their highest level of health. For example, institutional racism have placed policies and practices that have confined African American/Black populations to poor areas and neighborhoods containing toxic waste. Thus, toxic metals such as $\mathrm{Pb}$, can potentially add to stressors at both the neighborhood- and individual-level, interacting with other social determinants of health increasing the risk for PTB and the likelihood of mother/infant mortality and morbidity in conjugation of race or poverty level. 


\subsection{Perspective of Previous Studies}

Prior research shows that detrimental health outcomes related to $\mathrm{Pb}$ exposure date as far back as 1911, following the industrial age of the United States [26]. At that time, $\mathrm{Pb}$ was a component added to gasoline, paint, and commercial pipes before an industrial ban was enacted in the 1970's [3,7,8]. This ban effectively reduced new exposure but did not guarantee the eradication of existing $\mathrm{Pb}$ circulating in the lived environment. Moreover, neighborhoods with hazardous waste sites were environmentally burdened by additional sources of lead. Thus, environmental exposure to $\mathrm{Pb}$ in these neighborhoods may occur through proximity to leaching of $\mathrm{Pb}$ from contaminated hazardous waste sites and neglected housing $[27,28]$.

In SF, more than $80 \%$ of the homes built before 1979 are coated with Pb-based paints [23]. Pb-containing paint becomes hazardous when it starts to peel, crack, or is otherwise disturbed by repairs or renovation projects and is inhaled, ingested, and absorbed over time. In fact, a study conducted from 2008 to 2012 in SF using blood biospecimens from children showed increased $\mathrm{Pb}$ levels from $6.6 \%$ to $11.8 \%$ as city renovation projects increased. Many of these children lived in poor neighborhoods [23]. Low-income, densely populated, and racially minoritized $\mathrm{SF}$ neighborhoods with higher $\mathrm{Pb}$ levels are also proximal to EPA exposure sites (Figure 3).

The connection among high-risk communities, waste sites, and $\mathrm{Pb}$ contaminated housing can be explained by historical neighborhood redlining practices also linked to adverse birth outcomes $[29,30]$. Redlining - the state-sanctioned ranking of neighborhood desirability for lending purposes-created clustering of racial groups in cheaply constructed, poorly maintained, and underfunded housing and community buildings. These previously ostracized and infrastructural neglected neighborhoods are currently undergoing renovation projects exposing the community to debris and potentially heavy metals $[23,29,30]$.

Like other heavy metals, $\mathrm{Pb}$ exposure is associated with chronic stress, oxidative DNA damage, and elevated prenatal stress during pregnancy [31]. During pregnancy, toxic chemicals that accumulate in the mother's body over time can deposit in the fetus leading to low birth weight and PTB $[1,18,20,21,32]$. PTB and other adverse health outcomes affecting the mother and fetus are a consequence of chronic inflammatory responses caused directly and indirectly by environmental chronic stressors such as $\mathrm{Pb}$ [31,33-36]. $\mathrm{Pb}$ is also associated with disruption of the reproductive system in both male and female sexes $[20,21]$. Examples in males include abnormal spermatogenesis, chromosomal damage, infertility, abnormal prostatic function, and changes in testosterone [27,37]. Examples in females include susceptibility to infertility, miscarriages, premature membrane ruptures, preeclampsia, pregnancy hypertension, and premature delivery [27,37].

\subsection{Implications of Findings}

$\mathrm{Pb}$ exposure is detrimental to women's reproductive health and disproportionately affects marginalized individuals, namely, those who live below the poverty line and in low-income areas near poorly maintained industrialized facilities. Waste sites, construction sites, and older buildings are all potential sources of exposure to continuous $\mathrm{Pb}$ leaching. In fact, their geographical overlap in SF indicates how disenfranchised residents are exposed to heavy metals and why they are at higher risk for reproductive health disparities [5,25]. For example, the geospatial data (Figure 3) shows that Eastern SF has EPA sites located approximately five miles away from areas with higher levels of factors significantly associated with PTB in this study: Pb concentrations in hair, high poverty/low-income, and a dense African American/Black population.

Poverty, high $\mathrm{Pb}$ exposure, and a large population of African American/Black seem to be factors that permeate the Bayview Hunters Point neighborhood. Many of its residents live in public or subsidized housing that is often not well maintained [10]. It is home to lowincome and high-minoritized populations and is densely populated by industrial companies, toxic waste sites, and other sources of contamination. For example, this neighborhood was home to a federal Superfund site in the Hunters-Point Naval Shipyard (NRDL), which 
continues to house the PG\&E Hunters-Point Power Plant, and the largest sewage treatment plant in SF. NRDL activities contaminated the soil, surface and groundwater with heavy metals, among other toxins [9-11]. As a result, both residents and the environment continue to be impacted by both stationary and mobile pollution sources, including radioactive and toxic contamination at the superfund site and nearby waterfront [10]. The most recent CalEnviroScreen report concluded that there is continued leaching of these toxins and that the impact on residential health has contributed to a higher prevalence of asthma, cardiovascular disease, and low birth weight over the years [23].

The health implication of long-term exposure to environmental toxins includes poor birth outcomes, mental retardation, infertility, and disability-adjusted life-years in the US. These adverse health outcomes affect SF's workers and residents, making this a considerable and serious public health and environmental justice concern [38].

\subsection{Future Directions}

Further studies should regularly monitor human exposure to $\mathrm{Pb}$ and other common heavy metals by measuring its levels in workers and residents using non-invasive methods like the collection of hair. The results obtained by determining the concentration of $\mathrm{Pb}$ in the collected hair should be shared with stakeholder communities using online geospatial tools. These tools allow for readily understandable visualization of the data. Additionally, healthcare policies should be changed and resources made available to facilitate secondary prevention methods for $\mathrm{Pb}$ exposure. Specifically, toxic screening panels should be added to annual routine check-ups, especially in children, high-risk women of childbearing age, and those living in areas near heavy construction and or waste disposal sites. Additionally, resources should be made available to educate the community on signs of heavy metal toxicity and recommended steps to address the effects exposure.

Heavy metal exposure is not unique to SF. Flint is a city in Michigan where Pb-tainted water sources created a cascade of health problems affecting community health $[39,40]$. Similar health disparities have appeared in older metropolitan cities in states like Pennsylvania, New York, and Iowa with elevated levels of environmental toxins associated with adverse symptoms in children $[5,20,23]$. Consequently, at the national level, future directions include routine evaluation of current policy and regulatory practices to identify successful policy and interventions, and strengthen enforcement against those who neglect proper hazardous waste disposal practices.

\section{Limitations and Delimitations}

This current ecological study design and non-purposive sampling preclude causal interpretation and generalizability of results beyond the 26 zip codes studied. Further, the small sample size increased the likelihood of committing a Type II error. A key delimitation of this study is that out of all the salons and barbershops in SF, 125 were randomly invited to participate to capture a sample of the population. Sampling of hair from local businesses increased randomization, but it did not guarantee that all the hair samples collected in one business only belonged to residents of that zip code. The collection of hair samples used was considered less invasive and a more accessible method of collecting biospecimens from the public, especially those who are hesitant to engage in research. In future studies, these findings could be corroborated by measuring heavy metal levels in both blood and hair to have both real-time and cumulative data. A limitation of the current approach regarding $\mathrm{PTB}$ is the inability to link $\mathrm{Pb}$ concentrations obtained at the neighborhood level to pregnancy. This limitation could be overcome in future studies by recruiting pregnant women from SF neighborhoods to donate biospecimens to measure exposure to environmental chemicals during pregnancy, after birth, and in their child.

\section{Conclusions}

In this study, environmental exposure of $\mathrm{Pb}$ in $\mathrm{SF}$ zip codes and its associations with determinants of health was examined by race, poverty and PTB rates. Leveraging 
the social-ecological model (Social-ecological models recognize individuals as embedded within larger social systems and describe the interactive characteristics of individuals and environments that underlie health outcomes [41]), we examined environmental exposure of $\mathrm{Pb}$ in neighborhoods by aggregating hair samples from multiple individuals within each zip code. Using zip codes as a proxy for municipality allowed us to analyze the interactions among $\mathrm{Pb}$ exposure, PTB rates, and determinants of health at the community level.

$\mathrm{Pb}$ levels were found in human hair at the individual-level that can plausibly be explained through environmental exposure. The $\mathrm{Pb}$ measured was geospatially correlated with higher rates of preterm birth, poverty, low-income, and higher density of African American/Blacks in San Francisco. Notably, San Francisco local businesses in hard-to-reach communities were engaged and were the primary sites of biospecimen donation used in this analysis. The findings are unique because of the translational community-engaged study design, successful recruitment of racially underrepresented study participants, and the visualization of significant interactions with geospatial mapping.

This important study highlights the need for more translational community-engaged research to bridge the gap between traditional science and epidemiological research to illustrate a clear picture of health disparities. In particular, this study shows how social determinants including toxic environmental exposures exacerbate health disparities at the individual and community level $[9,35]$.

Supplementary Materials: The following are available online at https:/ /www.mdpi.com/article/10 .3390/ijerph19010086/s1: Figure S1: Calibration Curve for Pb in Hair was set the following intensity1000, 200, 100, 50 ppb and Pb was highly detectable; Table S1: Characteristics of Collected Hair samples-this represents the sample mean of the San Francisco population from participating hair salons that donated hair samples $(n=108)$; Table S2: Unpaired $t$-test (two-sample $t$-test with unequal variances); Table S3: Linear regression of continuous $\mathrm{Pb}$ concentration on preterm birth among hair samples from hair salons across $19 \mathrm{SF}$ zip codes/neighborhoods $(n=108)$; Table S4: Linear regression of categorical $\mathrm{Pb}$ concentration on preterm birth among hair samples from hair salons across $19 \mathrm{SF}$ zip codes/neighborhoods $(n=108)$.

Author Contributions: Conceptualization, C.N.O. and L.M.-M.; Methodology, C.N.O. and R.M.M.; Software, C.N.O.; Validation, C.N.O.; Formal Analysis, C.N.O. and M.D.T.; Investigation, C.N.O. and E.C.D.G.; Resources, L.M.-M.; Data Curation, C.N.O.; Writing-Original Draft Preparation, C.N.O.; Writing-Review \& Editing, C.N.O., M.D.T., E.C.D.G., R.M.M., N.S.R. and L.M.-M.; Visualization, C.N.O.; Supervision, L.M.-M.; Project Administration, R.M.M.; Funding Acquisition, L.M.-M. All authors have read and agreed to the published version of the manuscript.

Funding: This research was funded by the National Institutes of Health (NIH) Building Infrastructure Leading to Diversity (BUILD) Award \#UL1 GM118985, and supported by the San Francisco State University Health Equity Research (HER) Lab.

Institutional Review Board Statement: The study was conducted according to the guidelines of the Declaration of Helsinki, and approved by the Institutional Review Board (or Ethics Committee) of San Francisco state University (IRB\# E13-169 approved 2016).

Informed Consent Statement: Informed consent was obtained from all subjects involved in the study.

Data Availability Statement: More about data availability sources you can find in the Supplementary Material.

Acknowledgments: We wish to acknowledge master's thesis committee, and members of the study team that contributed to this research. Thanks to the following faculty for their guidance and support: Pete Palmer. Analytical-Environmental Chemist, and faculty, Department of Chemistry/Biochemistry at SFSU; Plueni Pennings. Department of Biology at SFSU; Joshua Robinson. Department of Obstetrics, Gynecology, \& Reproductive Sciences at UCSF. Thank you to the Cathy Samayoa-HER lab, SFSU Chemistry and Biochemistry department, SFSU Biology department/stockroom staff \& facility, biology department PINC program, Audrey Parangan-Smith—SF BUILD staff and UCSF staff for their ongoing partnership in the research and special thanks to Biology Yedidiya Ayele Sefer and budding researcher Eyuche O. Okorie, NexGeneGirls. Thanks also extended to SFSU supporters from Biology department Darleen Franklin, Biology Instructional Services Facility Supervisor in 
Department of Biology, and Blake Riggs Department of Biology and the A. Philip Randolph Institute (APRI) San Francisco. Finally, sincere gratitude to Hair salons across San Francisco and the study participants for their contribution to this research.

Conflicts of Interest: All the authors declare no conflict of interest.

\section{References}

1. Romero, R.; Dey, S.K.; Fisher, S.J. Preterm labor: One syndrome, many causes. Science 2014, 345, 760-765. [CrossRef]

2. Braveman, P.; Gottlieb, L. The social determinants of health: It's time to consider the causes of the causes. Public Health Rep. 2014, 129, 19-31. [CrossRef]

3. Kim, H.-C.; Jang, T.-W.; Chae, H.-J.; Choi, W.-J.; Ha, M.-N.; Ye, B.-J.; Kim, B.-G.; Jeon, M.-J.; Kim, S.-Y.; Hong, Y.-S. Evaluation and management of lead exposure. Ann. Occup. Environ. Med. 2015, 27, 30. [CrossRef] [PubMed]

4. United States Department of Labor. 1910.1025 App A-Substance Data Sheet for Occupational Exposure to Lead, Occupational Safety and Health Administration. OSHA. 1991. Available online: https://www.osha.gov/laws-regs/regulations/ standardnumber/1910/1910.1025AppA (accessed on 28 June 2020).

5. Curtis, C.; Reiter, R. Data Brief: Birth Data for San Francisco Residents 2012; San Francisco Department of Public Health-Maternal, Child \& Adolescent Health: San Francisco, CA, USA, 2012; p. 6. Available online: https://www.sfdph.org/dph/files/MCHdocs/ Epi/Birth-Data-Summary-SF.pdf (accessed on 27 July 2019).

6. Maness, S.B.; Buhi, E.R. Associations between social determinants of health and pregnancy among young people: A systematic review of research published during the past 25 years. Public Health Rep. 2016, 131, 86-99. [CrossRef]

7. United States Department of Labor. Substance Data Sheet for Occupational Exposure to Lead-1910.1025 App A. OSHA. 1991. Available online: https://www.osha.gov/pls/oshaweb/owadisp.show_document?p_table=STANDARDS\&p_id=10031 (accessed on 28 June 2020).

8. United States Department of Labor. OSHA Fact Sheet: Protecting Workers from Lead Hazards. Occupational Safety and Health Administration. OSHA. Available online: https://www.osha.gov/OshDoc/data_Hurricane_Facts/LeadHazards.html (accessed on 11 May 2020).

9. Hirsch, D.; Altenbern, T.; Caine, M.; Williams, H.; Gortner, D. Hunters Point Shipyard Cleanup Used Outdated and Grossly Non-Protective Cleanup Standards. 2018. Available online: https:/ /www.committeetobridgethegap.org/wp-content/uploads / 2018/10/HuntersPtReport3CleanupStandards.pdf (accessed on 10 May 2020).

10. Bayview Hunters Point Mothers Environmental Health \& Justice Committee; Huntersview Tenants Association; Greenaction for Health \& Environmental Justice. Pollution, Health, Environmental Racism and Injustice: A Toxic Inventory of Bayview Hunters Point, San Francisco. September 2004. Available online: https://greenaction.org/wp-content/uploads/2019/06/ thestateoftheenvironment090204final.pdf (accessed on 25 March 2021).

11. US EPA. Hunters Point Naval Shipyard San Francisco, CA. Superfund Site. Available online: https://cumulis.epa.gov/supercpad/ cursites / csitinfo.cfm?id=0902722 (accessed on 18 November 2019).

12. Barbosa, F.; Tanus-Santos, J.E.; Gerlach, R.F.; Parsons, P. A Critical Review of Biomarkers Used for Monitoring Human Exposure to Lead: Advantages, Limitations, and Future Needs. Environ. Health Perspect. 2005, 113, 1669-1674. [CrossRef] [PubMed]

13. PBHA-Clinical: Lead, Hair. 1995. Available online: https://www.mayomedicallaboratories.com/test-catalog/Clinical+and+ Interpretive/8495 (accessed on 15 April 2018).

14. Nowak, B.; Chmielnicka, J. Relationship of lead and cadmium to essential elements in hair, teeth, and nails of environmentally exposed people. Ecotoxicol. Environ. Saf. 2000, 46, 265-274. [CrossRef]

15. Niculescu, T.; Dumitru, R.; Botha, V.; Alexandrescu, R.; Manolescu, N. Relationship between the lead concentration in hair and occupational exposure. Occup. Environ. Med. 1983, 40, 67-70. [CrossRef]

16. Sreenivasa, R.K.; Balaji, T.; Prasada, R.T.; Babu, Y.; Naidu, G.R.K. Determination of iron, cobalt, nickel, manganese, zinc, copper, cadmium and lead in human hair by inductively coupled plasma-atomic emission spectrometry. Spectrochim. Acta Part B Spectrosc. 2002, 57, 1333-1338. [CrossRef]

17. Jan, A.T.; Azam, M.; Siddiqui, K.; Ali, A.; Choi, I.; Haq, Q.M.R. Heavy metals and human health: Mechanistic insight into toxicity and counter defense system of antioxidants. Int. J. Mol. Sci. 2015, 16, 29592-29630. [CrossRef]

18. Esteban-Vasallo, M.D.; Aragones, N.; Pollan, M.; Lopez-Abente, G.; Perez-Gomez, B. Mercury, cadmium, and lead levels in human placenta: A systematic review. Environ. Health Perspect. 2012, 120, 1369-1377. [CrossRef]

19. Woodruff, T.J.; Zota, A.; Schwartz, J.M. Environmental chemicals in pregnant women in the United States: NHANES 2003-2004. Environ. Health Perspect. 2011, 119, 878-885. [CrossRef]

20. Sanders, A.P.; Flood, K.; Chiang, S.; Herring, A.H.; Wolf, L.; Fry, R.C. Towards prenatal biomonitoring in North Carolina: Assessing arsenic, cadmium, mercury, and lead levels in pregnant women. PLoS ONE 2012, 7, e31354. [CrossRef] [PubMed]

21. Chen, Z.; Myers, R.P.; Wei, T.; Bind, E.; Kassim, P.; Wang, G.; Ji, Y.; Hong, X.; Caruso, D.; Bartell, T.; et al. Placental transfer and concentrations of cadmium, mercury, lead, and selenium in mothers, newborns, and young children. J. Expo. Sci. Environ. Epidemiol. 2014, 24, 537-544. [CrossRef] [PubMed] 
22. Ozer, E.; Van Baar, A.; De Jong, M.; Verhoeven, M.; Costa, F.O.; Erez, O.; Masho, S.; Brooks, H.J.L.; McConnell, M. Preterm Birth. 2013. Available online: https://www.sfdph.org/dph/hc/HCCommPublHlth/Agendas/2014/November_18/Preterm_Births_ FactSheet_SFDPH_v20140930k.pdf (accessed on 18 November 2019).

23. Shutt, J. Childhood Lead Levels in Some SF Neighborhoods Near Flint, MI Levels—Hoodline. 2017. Available online: http: //hoodline.com/2017/01/childhood-lead-levels-in-some-sf-neighborhoods-near-flint-mi-levels (accessed on 2 October 2017).

24. United States Census Bureau. American Community Survey, 2016 via Social Explorer. Social Explorer Profiles. 2019. Available online: https:/ / www.socialexplorer.com/profiles/essential-report/index.html (accessed on 30 June 2020).

25. Stookey, J.; Chan, C. Data Brief: Live Births, 2014; San Francisco Department of Public Health-Maternal, Child \& Adolescent Health: San Francisco, CA, USA, 2014; Available online: https:/ /www.sfdph.org/dph/files/MCHdocs/Epi/Updates12132016/ SF-BirthsDataBrief2014-12-12-2016.pdf (accessed on 18 November 2019).

26. Hamilton, A. Lead poisoning in the United States. 1914. Am. J. Public Health 2009, 99 (Suppl. 3), S547-S549.

27. Flora, G.; Gupta, D.; Tiwari, A. Toxicity of lead: A review with recent updates. Interdiscip. Toxicol. 2012, 5, 47-58. [CrossRef] [PubMed]

28. Wani, A.L.; Ara, A.; Usmani, J.A. Lead toxicity: A review. Interdiscip. Toxicol. 2015, 8, 55-64. [CrossRef] [PubMed]

29. Nardone, A.L.; Casey, J.A.; Rudolph, K.E.; Karasek, D.; Mujahid, M.; Morello-Frosch, R. Associations between historical redlining and birth outcomes from 2006 through 2015 in California. PLoS ONE 2020, 15, e0237241. [CrossRef]

30. Parker, J.D.; Schoendorf, K.C.; Kiely, J.L. Associations between measures of socioeconomic status and low birth weight, small for gestational age, and premature delivery in the United States. Ann. Epidemiol. 1994, 4, 271-278. [CrossRef]

31. Coussons-Read, M.E. Effects of prenatal stress on pregnancy and human development: Mechanisms and pathways. Obstet. Med. 2013, 6, 52-57. [CrossRef]

32. Lenntech, B.V. Lead (Pb)-Chemical properties, Health and Environmental Effects. 2017. Available online: https://www.lenntech. $\mathrm{com} /$ periodic/elements/pb.htm (accessed on 1 June 2018).

33. McEwen, B.S.; Wingfield, J.C. The concept of allostasis in biology and biomedicine. Horm. Behav. 2003, 43, 2-15. [CrossRef]

34. Smith, S.M.; Vale, W.W. The role of the hypothalamic-pituitary-adrenal axis in neuroendocrine responses to stress. Dialogues Clin. Neurosci. 2006, 8, 383-395.

35. Thomas, M.D.; Michaels, E.K.; Reeves, A.N.; Okoye, U.; Price, M.M.; Hasson, R.E.; Chae, D.H.; Allen, A.M. Differential associations between everyday versus institution-specific racial discrimination, self-reported health, and allostatic load among black women: Implications for clinical assessment and epidemiologic studies. Ann. Epidemiol. 2019, 35, 20-28. [CrossRef] [PubMed]

36. Thomas, M.D.; Sohail, S.; Mendez, R.M.; Márquez-Magaña, L.; Allen, A.M. Racial discrimination and telomere length in midlife African American women: Interactions of educational attainment and employment status. Ann. Behav. Med. 2021, 55, 601-611. [CrossRef]

37. Flora, S.J.S.; Pachauri, V.; Saxena, G. Arsenic, cadmium and lead. In Reproductive and Developmental Toxicology; Elsevier Inc.: Amsterdam, The Netherlands, 2011; pp. 415-438.

38. Tchounwou, P.B.; Yedjou, C.G.; Patlolla, A.K.; Sutton, D.J. Heavy metal toxicity and the environment. Mol. Clin. Environ. Toxicol. 2012, 101, 133-164. [CrossRef]

39. City of Flint, Michigan. State of Emergency Declared in the City of Flint. State of Emergency. 2016. Available online: https: //www.cityofflint.com/state-of-emergency (accessed on 21 April 2018).

40. Kristof, N. America is flint. The New York Times, 6 February 2016, pp. 5-8. Available online: https://www.nytimes.com/2016/0 2/07/opinion/sunday/america-is-flint.html (accessed on 18 November 2019).

41. Golden, S.D.; Earp, J.A.L. Social Ecological Approaches to Individuals and Their Contexts: Twenty Years of Health Education \& Behavior Health Promotion Interventions. Health. Educ. Behav. 2012, 39, 364-372. 